\title{
EFFICIENT DIVERSIFICATION ACCORDING TO STOCHASTIC DOMINANCE CRITERIA
}

\author{
Timo Kuosmanen \\ Wageningen University, Environmental Economics and Natural Resources Group, Hollandseweg 1, \\ 6706KN Wageningen, The Netherlands, Tel. +31 317 484738, Fax. +31 317 484933, E-mail. \\ Timo.Kuosmanen@wur.nl
}

This on-line attachment presents an application of the Stochastic Dominance tools, which was excluded from the main paper to save space. The purpose of this application is to further illustrate the possible uses of the SD techniques developed in the main paper.

\section{Application to Forest Management}

The SD approach has its greatest application potential in areas where the usual MV assumptions are severely violated. One promising application area is natural resource management, where nonnormal return distributions are often observed. This on-line appendix re-examines the timber-harvesting problem of Heikkinen (1999) from the SD perspective. For a more detailed treatment, a reader is referred to Heikkinen and Kuosmanen (2003).

It has become increasingly popular to model forest management problems as a part of the risk management of a mixed portfolio consisting of timber-stock as well as financial assets. A forest can be considered an investment alternative that has a relatively low risk. The physical growth of timber provides a safe return, but financial risks still arise from the inter-temporal fluctuations of stumpage prices and rare "catastrophic" events such as fire, storm, or pest damages. Applying the standard MV criteria, Heikkinen studied a forest estate in Eastern Finland, consisting of 22.6 hectares of forest that is officially partitioned into 14 stands according to geographic location. Each stand has a unique mixture of tree species, assortment to sawlogs versus pulpwood, as well as physical growth, and is managed independently. Logging is usually implemented by forest stand, not by tree assortment or species. Finnish forestry legislation forbids final felling of young stands. In the present case, final felling is allowed only in four stands between 70 and 90 years of age. Therefore, only the timber stock on those four specific stands can be considered a liquid asset. 
Table 4. Characteristics of the four harvestable stands

\begin{tabular}{lcccccc}
\hline & $\begin{array}{c}\text { Stand } \\
\# 162\end{array}$ & $\begin{array}{c}\text { Stand } \\
\# 163\end{array}$ & $\begin{array}{c}\text { Stand } \\
\# 165\end{array}$ & $\begin{array}{c}\text { Stand } \\
\# 173\end{array}$ & Total & $\begin{array}{c}\text { Prices } \\
€ / \mathrm{m}^{3}\end{array}$ \\
\hline $\begin{array}{l}\text { Pine sawlogs } \\
\text { Spruce sawlogs }\end{array}$ & $67 \mathrm{~m}^{3}$ & $16 \mathrm{~m}^{3}$ & $17 \mathrm{~m}^{3}$ & & & 41.73 \\
Birch sawlogs & & & $267 \mathrm{~m}^{3}$ & & 34.66 \\
$\begin{array}{l}\text { Pine pulpwood } \\
\text { Spruce pulpwood }\end{array}$ & $25 \mathrm{~m}^{3}$ & $9 \mathrm{~m}^{3}$ & $16 \mathrm{~m}^{3}$ & & & 16.50 \\
Birch pulpwood & & $3 \mathrm{~m}^{3}$ & $14 \mathrm{~m}^{3}$ & $191 \mathrm{~m}^{3}$ & & 41.53 \\
Total & $92 \mathrm{~m}^{3}$ & $31 \mathrm{~m}^{3}$ & $47 \mathrm{~m}^{3}$ & $485 \mathrm{~m}^{3}$ & $628 \mathrm{~m}^{3}$ & \\
\hline Growth (\%) & 3.2 & 4.1 & 4.1 & 3.7 & & \\
Value (€) & 2,843 & 940 & 1,195 & 13,232 & 18,210 & \\
Portfolio weight & 0.16 & 0.05 & 0.07 & 0.72 & & \\
Area (ha) & 0.7 & 0.5 & 0.6 & 2.2 & 4 & \\
\hline
\end{tabular}

Table 4 presents descriptive statistics about timber species and assortments, growth, monetary value, weight in the original portfolio, and land area of the four stands considered. Two stands consisted primarily of spruce sawlogs and pulpwood, the other two mainly of pine sawlogs and pulpwood. The annual growth of stands varied between 3.2 and 4.1 percents. The total timber volume of these four stands was $628 \mathrm{~m}^{3}$ with a value of 18,210 Euro (using prices from 12/1996).

The crux of this application is in the possibility to hedge forestry risks through diversifying a part of the wealth to the stock-market. For simplicity, we use the general stock market index of the Helsinki Stock Exchange (HEX) to represent equities as an alternative investment possibility. Monthly arithmetic averages of the daily closing values of HEX were calculated to make data comparable to stumpage prices, which are reported on monthly basis. Our historical data ranges from 10/1985 to 12/1996. During this period, the stock market of Helsinki offered a mean return of sixteen percent per annum, with a standard deviation of twentyone percent. The forest stands offered a much more modest growth with a mean return of approximately six percent. This growth, however, was more stable; the standard deviation of the rates of return varied from seven to ten percent for all sfour forest stands.

The forest owner's investment problem is to allocate his liquid timber assets, worth 18,210 Euro, in a productive way in order to maximize the wealth at the end of the planning period. Two basic shortterm strategies are considered. The first is to harvest the timber immediately and invest in equities traded in the stock market. The second is to postpone harvesting to the future in order to yield an additional physical growth and potentially sell timber for a higher price. Of course, both the stock market 
and future timber prices are risky. For the present purposes we consider the physical growth to be deterministic.

Besides the two pure strategies discussed above, a full continuum of ' mixed' diversified strategies are considered. Since we do not consider land sales but rather timber harvesting, the liquid timber asset can be considered perfectly divisible. For example, it is possible to harvest $100 \cdot b$ percent $(0 \leq b \leq 1)$ of liquid timber and invest logging returns in the stock market, and hedge the risk by leaving the remaining $100 \cdot(1-b)$ percent of timber to be harvested in the future. The risk profile of the total portfolio can be influenced by targeting logging at specific stands, that is, it is not necessary to harvest all stands at the same degree. However, we restrict our attention to final logging in the sense that it is not possible (or cost effective) to target harvest to specific species within any given stand in order to change the composition (and thus the risk profile) of the stand. By this simplification, the historical rates of return for each forest stand can be computed as the sum of physical growth and the average increase in stumpage prices, weighted by the composition (i.e., species and thickness) of timber.

As a preliminary step, we tested for normality of return distributions using the standard ShapiroWilks test. The null hypothesis of normality was rejected at a $99 \%$ confidence level or higher for all five assets. This gives a strong empirical motivation for the SD approach. By visual inspection all assets appeared to have a bell-shaped distribution symmetric around the mean. Normality was violated mainly because of high kurtosis, not because of any notable skewness.

We next examined the SD test presented in the Section 4. The test statistics $\theta_{1}, \theta_{2}^{n}, \theta_{2}^{s}$, and $\hat{\theta}_{2}^{n}$ were calculated for the original, observed portfolio with weights $\lambda_{162}=0.16, \lambda_{163}=0.05$, $\lambda_{165}=0.07, \lambda_{173}=0.73$, and $\lambda_{H E X}=0.00$. Following Heikkinen (1999), we considered two alternative specifications of portfolio weight domain:

1) the "unconstrained case": $\Lambda=\left\{\lambda \in \mathbb{R}_{+}^{5} \mid \sum \lambda_{i}=1\right\}$, and

2) the "constrained case":

$$
\Lambda=\left\{\lambda \in \mathbb{R}_{+}^{5} \mid \sum \lambda_{i}=1 ; \lambda_{162} \leq 0.16 ; \lambda_{163} \leq 0.05 ; \lambda_{165} \leq 0.07 ; \lambda_{173} \leq 0.73\right\}
$$


The usual interpretation of portfolio weights applies; weight of a forest stand represents the proportion of wealth that is held in that particular stand. The portfolio weight of a forest stand can be decreased by harvesting timber. In contrast, increasing the portfolio weight of a forest stand means acquiring additional growing timber stock of similar quality to the existing stand. Since each stand has a unique composition of timber species and assortment, increasing the portfolio weight is complicated or even impossible in the short run. These observations motivate the constrained case. The unconstrained case is considered merely for the sake of comparison. Recall that test statistic $\hat{\theta}_{2}^{n}$ cannot be calculated for the constrained case. For simplicity, short sales are excluded in both specifications.

Table 5: Values of SD test statistics in the Unconstrained and Constrained cases

\begin{tabular}{lcccc}
\hline & $\theta_{1}$ & $\theta_{2}^{n}$ & $\theta_{2}^{s}$ & $\hat{\theta}_{2}^{n}$ \\
\hline 1) Unconstrained case & 0.0008 & 0.0008 & - & 0.4920 \\
2) Constrained case & 0.0000 & 0.0000 & 8978.00 & n.a. \\
\hline
\end{tabular}

Table 5 reports the results of the SD tests. In the unconstrained case, $\theta_{1}, \theta_{2}^{n}>0$, and $\widehat{\theta}_{2}^{n}<1$, which means that all test statistics diagnose the present forest portfolio as SD inefficient (in terms of both FSD and SSD). Statistic $\hat{\theta}_{2}^{n}$ confirms the inefficiency diagnosis, but does not provide any new information. Statistics $\theta_{1}$ and $\theta_{2}^{n}$ reveal that the mean return could be increased without altering the risk profile, but only by a mere 0.08 percentage points. Since the FSD efficiency measure equals the SSD efficiency measure, this result does not depend on the risk-preferences of the forest owner. As the necessary condition was already violated, the sufficient $\theta_{2}^{s}$ statistic has been omitted as redundant.

From the optimal solutions of the binary MILP problem (1) and the LP problem (2), we learn that $\lambda_{162}^{*}=0.906$ and $\lambda_{H E X}^{*}=0.094$. That is, the maximum rate of return with the current risk profile could be obtained by harvesting all other stands, and using the generated income to acquire additional timber-stock with a profile similar to that of Stand \#162. In the short run, this would necessitate purchasing additional mature spruce forest with more than 70 percent of timber suitable for sawlogs. In the Finnish market, such forest stands are not common. Therefore, the constrained market set, which 
limits portfolio weights of forest stands to be less than or equal to their current shares, seems a more realistic benchmark.

By construction, statistic $\hat{\theta}_{2}^{n}$ cannot incorporate additional constraints on portfolio weights. Therefore, we only consider problems (1) - (3) in the constrained case. Interestingly, the original portfolio reveals itself as efficient in terms of both FSD and SSD. That is, the current forest portfolio is the optimal expected utility maximizing choice for at least some non-satiated (by FSD) and risk-averse (by SSD) investors. In other words, we can rationalize the observed emphasis on forest assets in the constrained case. Of course, this does not imply that the risk profile of the current portfolio optimally matches the forest owner's preferences. It merely highlights that it is not possible to find a preferable alternative portfolio without first learning more about the forest owner's preferences.

Finally, let us briefly compare our SSD results to those of the MV analysis of Heikkinen. The MV approach minimizes variance of the portfolio, given an exogenously specified target mean return. From the scenarios considered by Heikkinen, the case of a 6 percent mean return target is closest to the original mean return of 5.9 percent. In the unconstrained case, the MV approach also diagnoses the original portfolio as inefficient; the MV efficient diversification strategy decreases the portfolio variance by 12.9 percent. Notably, the efficient portfolio also involves a similar type of land-trading and harvesting strategy, concentrating as much as 43.5 percent of the total wealth in a forest similar to Stand \#162. In the case of a land-trading constraint, however, the SD and MV approaches yield different qualitative results, namely, the SD criteria diagnoses the original portfolio as efficient while the MV criterion suggests inefficiency. However, the MV efficient benchmark portfolio at the target mean return of 6 percent does not deviate substantially from the original forest portfolio. In fact, only 2 percent of the total wealth is reallocated from the timber assets to the stock market. This would yield a mere 1.8 percent decrease in the portfolio variance.

Given these results, most risk-averse forest managers would probably postpone harvesting and preserve the present portfolio. Indeed, both SD and MV fail to demonstrate any significant gains by further diversifying the portfolio in terms of higher mean return or lower variance. This conclusion is confirmed by the sensitivity analysis. The procedure described in Section 6.1 was applied again to the 
forest portfolios (i.e., we 500 random pseudo-samples were drawn with replacement, and the SSD efficiency measures were calculated for each). In the constrained case, 68.3 percent of the pseudosamples were found to be efficient, which suggests the original result is robust to sampling variations. In the unconstrained case this percentage was only 6.7. The mean inefficiency in the pseudo-samples was 0.028 percent points per annum in the constrained case and 0.181 percent points in the unconstrained case, with standard deviations of 0.062 and 0.226 , respectively. Even in the unconstrained case, the potential efficiency gains in mean return are rather minimal. These gains should be balanced against the potential additional costs of harvesting, which have not been accounted for in the present analysis. Such costs might include transaction costs resulting from radical changes in the investment strategy, environmental or aesthetic losses due to increased homogeneity of tree species, and a possible option value of postponing the semi-irreversible harvesting decision (i.e., newly planted trees take several decades to grow).

\section{References}

Heikkinen, V.-P. (1999): Cutting Rules for Final Fellings: A Mean-Variance Portfolio Analysis, Journal of Forest Economics 5(2), 269-284.

Heikkinen, V.-P., and T. Kuosmanen (2003): Stochastic Dominance Portfolio Analysis of Forestry Assets, Chapter 12 in J. Wesseler, H.-P. Weikard, and R. Weaver (Eds.): Risk and Uncertainty in Environmental and Natural Resource Economics, Edward Elgar, Cheltenham/Northampton. 